\title{
Results of an experimental study of a solar cooling system in Jaén using single effect lithium bromide absorption chiller
}

\author{
A. Gómez Moreno ${ }^{1}$, P.J. Casanova Peláez ${ }^{2}$, F.A. Díaz Garrido ${ }^{1}$, J.M. Palomar Carnicero ${ }^{1}$, \\ R. López García ${ }^{1}$, F. Cruz Peragón ${ }^{1}$ \\ ${ }^{1}$ Department of Mechanical and Mining Engineering \\ E.P.S. of Jaén, Jaén University \\ Paraje Las Lagunillas, s/n - Edificio A3, 23071 Jaén (España) \\ Telephone/Fax: +0034 953212903, e-mail: agmoreno@ujaen.es \\ ${ }^{2}$ Department of Electronic Engineering \\ E.P.S. of Jaén, Jaén University \\ Paraje Las Lagunillas, s/n - Building A3, 23071 Jaén (Spain) \\ Phone/Fax number:+0034 953212805, e-mail: casanova@ujaen.es
}

\begin{abstract}
.
The potential of absorption machines to cool, in particular, in house air-conditioning systems is well-known. Using solar thermal energy helps decreasing air-conditioning systems $\mathrm{CO}_{2}$ emissions. The purpose of this work is to prove the effectiveness of this kind of systems to cool an average house during summertime. The setting uses an unit heater for heat dissipation. The cooling coil decreases the COP setting because the dissipation depends on external temperature. Using another renewable source of energy, like geothermal energy (Ground Source Heat Pump, GSHP), would improve the performance of the setting because, from a certain depth, ground temperature is practically constant and it is lower. The goal of this article is to present the design of the system as well as some first results for several representative days in August 2009.
\end{abstract}

\section{Key words}

Cooling, Radiation, Solar, Efficiency, Absorption.

\section{Introduction}

Through the Housing Ministry, Spanish government, since April 2007, and by virtue of the new CTE (Spanish Building Technical Code) forces every newly built house to have a S.H.W. (Sanitary Hot Water) solar energy production system. In this context, another step to sustainable building would be using renewable sources of energy to cool.

One of the refrigeration cycles more widely used is the compression one, which uses as coolant CFCs. HCFCs and HFCs, that destroy the stratospheric ozone layer and contribute to the greenhouse effect. These drawbacks could be avoided using absorption chiller that uses organic coolant as water or ammonia, which do not contribute to climate change [1].
On the other hand, every process to improve energy efficiency needs a thermodynamics analysis as well as a subsequent optimization. Although there are articles analyzing solar refrigeration systems through simulations $[2,3]$, there is little information about experimental settings [4]. A theoretical survey based on experimental data will provide a more comprehensive analysis to optimize the system more efficiently, because even if there are some surveys in this sense, the absorption market is still under development.

\section{System analysis}

\section{A. Single effect lithium bromide absorption chiller}

The machine consists of four components that exchange energy with the surroundings, one internal heat exchanger, two flow restrictors, and a pump. The connecting piping between these devices is also important for design.

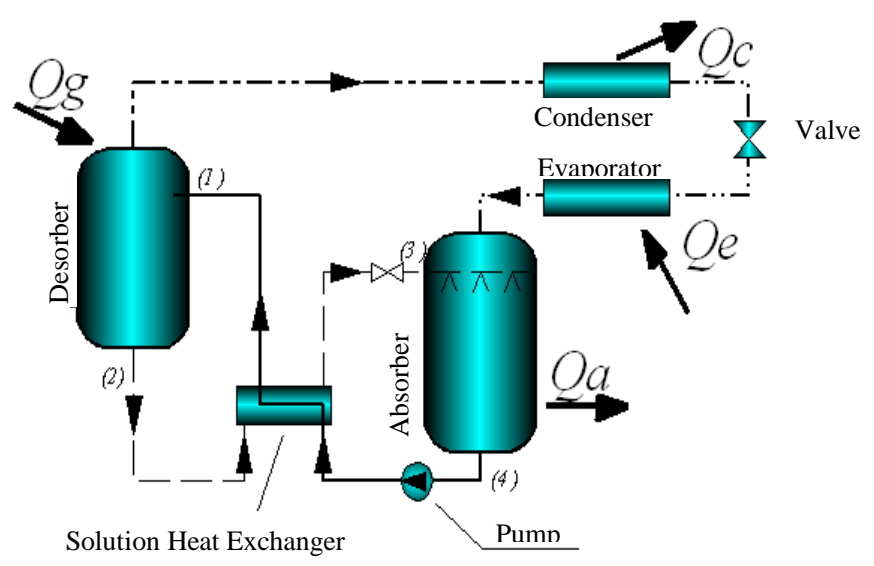

Fig. 1. Single-effect absorption cycle schematic 
The solution circuit circulates between the desorber and absorber. The liquid loop is pumped from the low pressure in the absorber to the high pressure in the desorber. As a first approximation, the entire machine can be considered to operate between two pressure levels.

There will be pressure losses associated with flow through the component and changes in elevation.

These losses must be minimized by design. An absorption chiller is a two-pressure device with significant pressure changes occurring only in the flow restrictors and the pump.

The liquid solution is pumped into the desorber where heat is supplied by external means such as a combustion source or any other source with a sufficiently high temperature, it can be used biomass energy or solar energy.

The required temperature level is governed by the properties of the working fluid and the operation of the other components in the machine. For a typical single effect aqueous lithium bromide machine the desorber heat must be supplied above temperature of approximately $90{ }^{\circ} \mathrm{C}$. When heat is applied to the solution, the volatile component (the refrigerant, water) is boiled of.

The machine selected 045 ROTARTICA Solar has a small power $(4.5 \mathrm{~kW})$ and smaller thanks to its rotary technology, which enables better processes of heat and mass transfer with the consequent reduction in size.
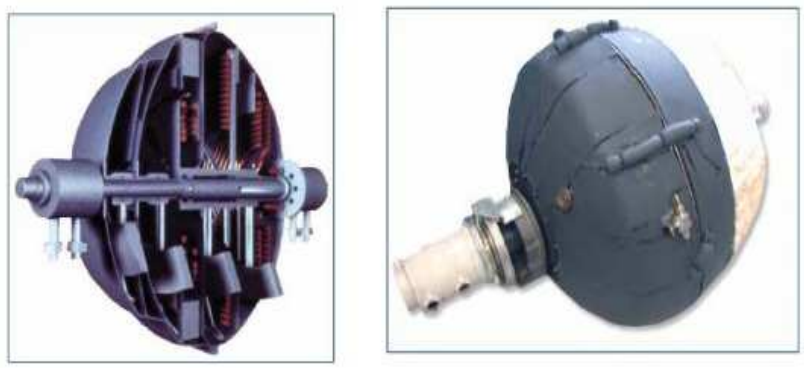

Fig. 2. Absorption chiller chosen.Rotártica 045

\section{B. Solar energy}

EERR plan provides for heating the target of 4,900,805 $\mathrm{m}^{2}$ of low temperature flat collector for 2010. In 2004 there were $700,805 \mathrm{~m}^{2}$, so applications should be encouraged to meet that objective.

Solar thermal energy is presented as a good alternative to supply heat into the desorber for various reasons [5]: demand for cooling is usually in stations with high solar radiation, can be used easily for S.H.W (sanitary hot water) and heating and it helps to solve the high power consumption which most often occur in summer. Local climatic conditions have a significant influence [6] in the collector performance, external factors such as humidity, wet bulb temperature and solar radiation are essential and they may vary considerably from year to year. It is therefore necessary to check during a period of time and experimentally the degree of influence of these values. Jaén is a province with privileged weather conditions [7] to launch air conditioning systems from renewable sources. High temperatures in summer make it possible for working fluids that circulate through the solar collectors can reach temperatures that allow the proper functioning of the absorption chiller. In addition, moderate temperatures in winter, make its use for heating is not excessively demanding.However, it must be tested experimentally to determine the influence of external variables on performance and to ensure technical and economic feasibility of using solar energy for cooling.

Once justified the solar potential in the province of Jaén, the next step is to determine the tilt of the collector to maximize energy gain. Figure 3 shows the estimated results of the incident energy in Jaén depending on the tilt angle of the collectors using a long-term radiation method [8].

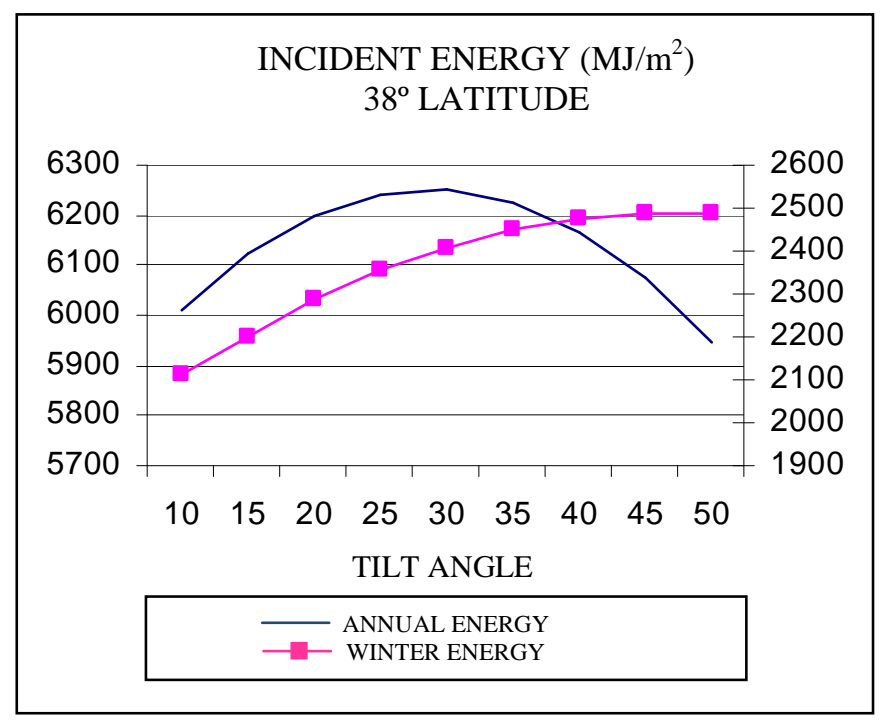

Fig. 3.Incident energy in Jaén

\section{Biomass energy}

In the absorption cycle, energy input in the desorber can be supplied by biomass combustion. Jaén has great potential of biomass. The olive growing so widely spread provides a large volume of waste, both from the tree (pruning), such as those resulting from the processes of primary processing of olive oil (residue) and secondary pomace oil (orujillo).

The desorber can function by direct or indirect heating. The machines running direct flame often work with combustible gases (butane, propane or natural gas) with clean and efficient combustion, so that the use of solid biomass can be tricky. It is interesting to evaluate how to provide indirect heating on the absorption chiller through the use of a boiler. Since the theoretical combustion temperature is well above the required temperature in the steam generator, this solution ensures optimal operating temperature. The advantage over solar systems is twofold: there are no restrictions on the temperature and there are no instant availability problems. 


\section{Geothermal energy}

Single effect lithium bromide absorption chiller has water as refrigerant, so the temperature in the evaporator can not decrease from $7{ }^{\circ} \mathrm{C}$. In addition, condensation and absorption processes are exothermic, requiring an auxiliary cooling equipment such as a cooling tower or similar. The problems resulting from its use in recent times (legionellosis) force to conduct a very thorough maintenance, which is expensive and dangerous. One possibility for improved efficiency in these devices is the use of ground as a heat source, either the cold or hot.

The European Union is particularly interested in developing this type of utilization of geothermal energy, called GSHP (Ground Source Heat Pump, heat pump with ground source), while in Spain practically does not apply [9].

The ground temperature is less than the ambient temperature during the summer, thereby replacing the use of cooling towers for geothermal energy can improve the efficiency of the system. Also, geothermal energy allows absorption chiller to be used as heat pump. In winter, ground is above $7^{\circ} \mathrm{C}$ at a certain depth so the absorption chiller could function as a heating system, with better efficiency than a conventional heating system or solar heating system. COP is obtained over 1 . This represents an advantage over conventional heating systems by direct combustion, whatever the source used (conventional fuels or biomass).

\section{Experimental set-up}

The air conditioning system designed allows future uses: 1.-Biomass boiler and solar collector as new heat imput.

2.-Use of geothermal energy.

3.-Use of underfloor heating.

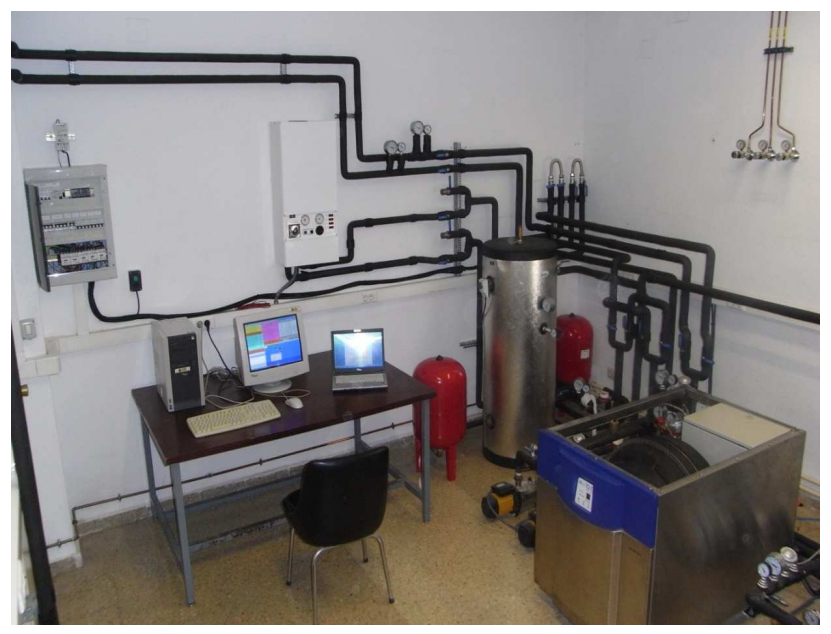

Fig. 4 Photograph of the installation

A complete system requires a large budget, so it have been developed a more simplified installation (Fig. 4). It consist of a single effect lithium bromide absorption chiller 4,5 kW (ROTARTICA 045,4,5 kw), two hot water storage tank, a heat sink, and one fan coil.

Plant is located at the University of Jaen and heated and cooled a laboratory with $42 \mathrm{~m}^{2}$ (Fig. 6).

Next it will be shown a general diagram of the designed installation (Fig 5).

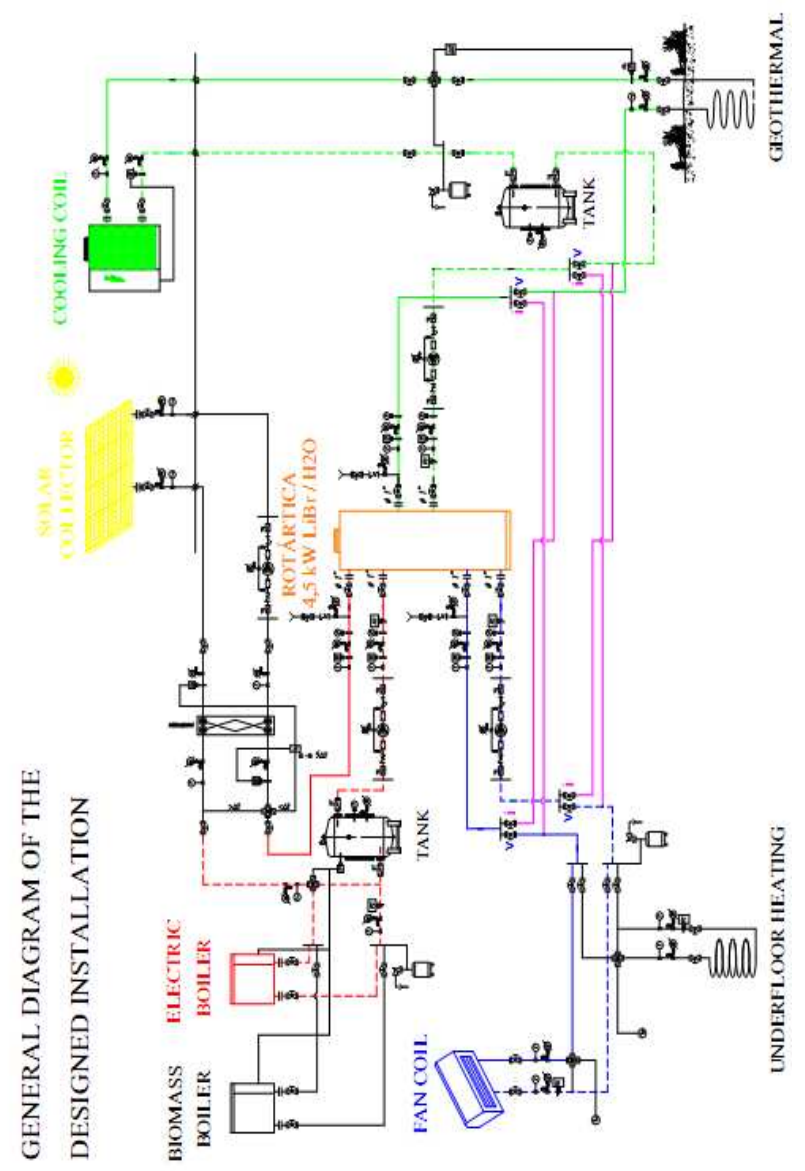

Fig.5 Scheme of the designed installation

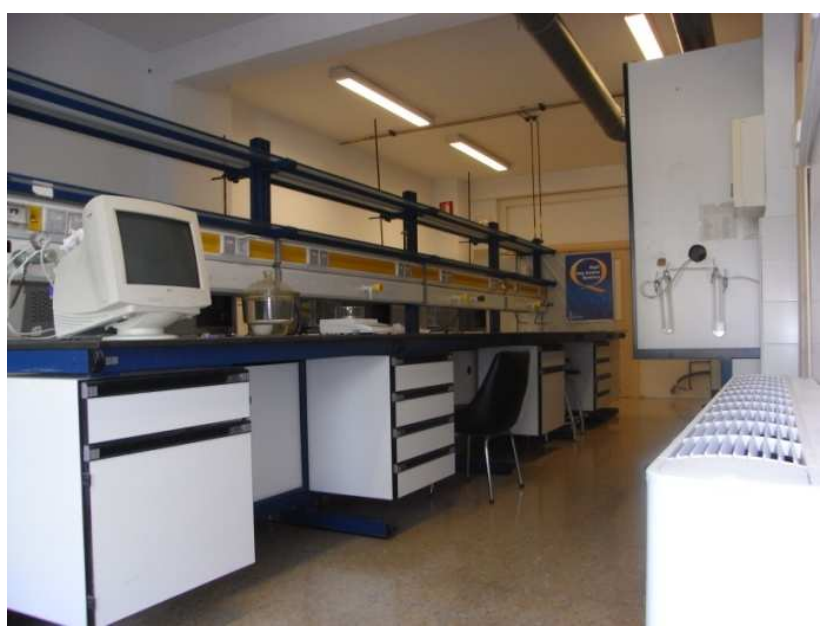

Fig.6 Photograph of the laboratory

For the acquisition data, plant is divided into two different subsystems. 'A' subsystem includes all the sensors located on the outside of the absorption chiller 
while the contents in this part is acquired by 'B' subsystems (Fig. 7).

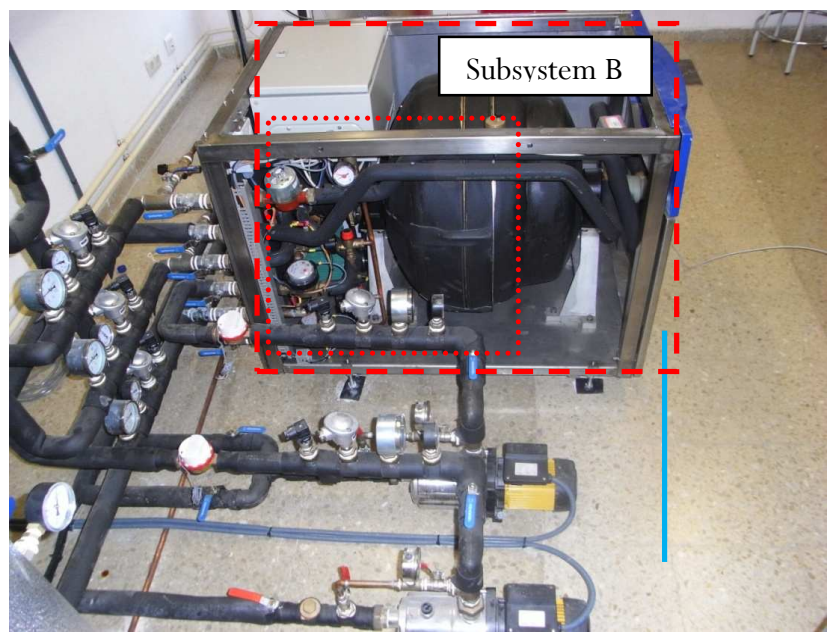

Fig. 7 Photograph of measuring equipment

The data acquisition is carried out every second and these data are stored in a computer. A program is developed in Visual Basic and it can generate daily files with data recorded from both subsystems.

'B' subsystem are recorded pressure and flow data of the three circuits present in the plant, generator, evaporator and heat sink. Also temperatures in and out of the three circuits are recorded. 'A' subsystem is repeated measures of subsystem $\mathrm{B}$, but now externally to the machine and with greater precision sensors. also external temperature and pressure are taken in addition to laboratory temperature

\section{Experimental results}

The flow in each water circuit was held constant while the chiller was in operation. The values recorded for the hot, chilled and cooling water circuits were 17,216 1/min, $26,414 \mathrm{l} / \mathrm{min}$ and $39,438 \mathrm{l} / \mathrm{min}$, respectively.

The experimental results for the generator, the evaporator and the fan coil on the three days selected for the trial are set out below.

- Warm day: 25/08/09

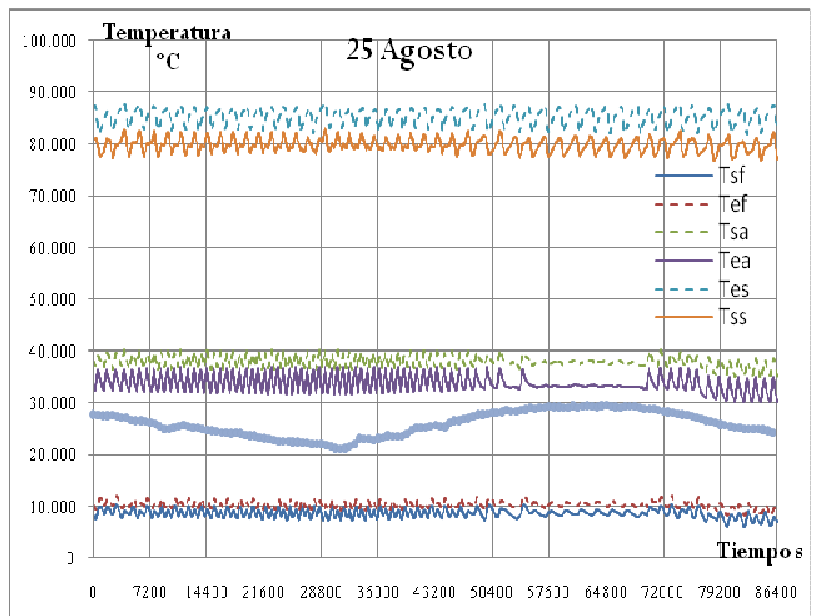

- Hot day: 25/08/09

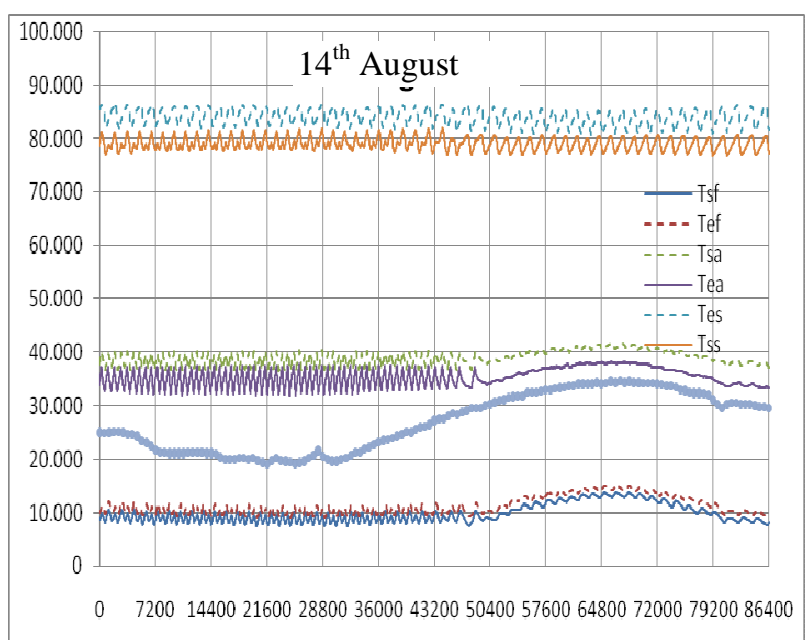

- Very hot day: 25/08/09

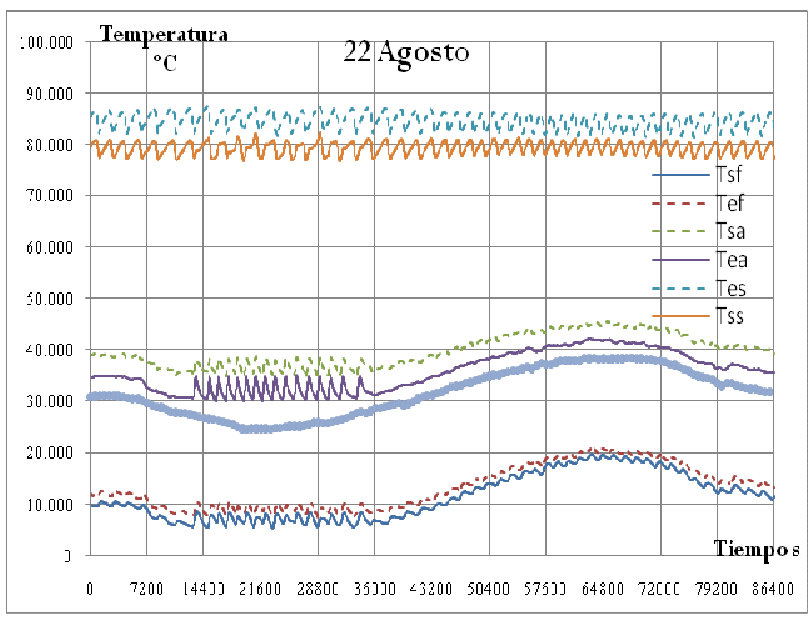

Fig. 8 Absorption Chiller operating temperature for warm, hot and very hot day. August 2009

For warm and hot days can be shown as the evaporator temperature is at all times below $14^{\circ} \mathrm{C}$, it ensures a comfortable temperature. However for a very hot day with external temperature near 40 degrees, the absorption chiller is unable to reach a temperature at evaporator outlet properly. In these cases, the use of geothermal energy presents itself as a very good solution

The hot water temperature in the generator ranged from 79 to $97^{\circ} \mathrm{C}$, with a difference of approximately $8{ }^{\circ} \mathrm{C}$ between the inlet and outlet temperatures.

\section{Conclusions}

The main contributions of the paper can be summarized as follows.

1.- The air-conditioning system designed in our university is very flexible because it can work as a heat pump and it allows future uses of different heat reservoirs as biomass or geothermal energy.

2.-The results presented are experimental and they show the good running or the absorption chiller during 
summertime in an installation developed in the University of Jaén.

\section{Acknowledgments}

This work is part of the University of Jaén Research Support Scheme and it is entitled: "Analysis of optimisation of renewable sources for cooling purposes. Applications in the province of Jaén ".(Code uja_07_17_01).

\section{References}

[1] Herold, K. E., Radermacher, R., Klein. S. A., Absorption Chillers and Heat Pumps, CRC Press, Taylor \& Francis Group, 1996.

[2] Assilzadeh F, Kalogirou SA, Ali Y, Sopian K., Simulation and optimization of a $\mathrm{LiBr}$ solar absorption cooling system with evacuated tube collectors Renewable Energy, 2005, 30, 1143-1159.

[3] Balaras CA, Grossman G, Henning H-M, Infante Ferreira CA, Podesser E, Wang L, Wiemken E., Solar air c onditioning in Europe-an overview. Renowable and Sustainable Energy Reviews, 2007, 11, 299-314.

[4] Henning H-M., Solar assisted air conditioning of buildingsan overview. Applied Thermal Engineerin, 2006,

[5] Izquierdo M, Leucoma A, Rodriguez $P$, Venegas M, Thermal Solar Energy for Spanish houses comfort: energy saving and environmental impact reduction. Proc. of 16th International Conference on Efficiency, Costs, Optimization, Simulation and Environmental Impact of Energy Systems, Copenhagen, 30 June-2 July 2003, pp. 657-664.

[6] Rodriguez P, Izquierdo M, Lecuona A, Venegas M, Sardina M, Rodriguez M C, López S, Decentralised cooling of electronic equipment using the thermal conversion of solar energy. ECEMEI 2004, 3rd European Congress on Economics and Management of Energy in Industry, Lisbon.

[7] Adsten M, Perers B, Wäckelgard E, The influence of climate and location on collector performance, Renewable Energy, 2002, 25 (4), 499-509.

[8]Alaíz Fernández E., Energía Solar. Cálculo y diseño de instalaciones, Publicaciones de la ETSI Industriales de la UPM, Madrid,1998.

[9] Eurobserv'ER, 6th Report State of Renewable Energies in Europe, 2006 